\title{
AN ECO FRIENDLY APPROACH FOR BATIK ON SILK USING NATURAL DYES AND DEVELOPMENT OF A COLOR PALETTE FOR A PRODUCT LINE
}

\author{
KAROLIA ANJALI ${ }^{1}$, YADAV RAJNI ${ }^{2}$ \& GANDHI HEMALI ${ }^{3}$ \\ ${ }^{I}$ Professor, Department of Clothing and Textiles, Faculty of Family and Community Sciences, \\ The Maharaja Sayajirao University Of Baroda, Vadodara, Gujarat, India \\ ${ }^{2}$ Temporary Assistant Professor, Department of Clothing and Textiles, Faculty of Family and Community Sciences, \\ The Maharaja Sayajirao University Of Baroda, Vadodara, Gujarat, India \\ ${ }^{3}$ MSc. Students, Department of Clothing and Textiles, Faculty of Family and Community Sciences, \\ The Maharaja Sayajirao University Of Baroda, Vadodara, Gujarat, India
}

Batik is one of the world's oldest living crafts and art forms. It has survived so long, adapting and evolving along the way, and still is made in many parts of the world, by both traditional and contemporary means and suggests, it has some wisdom to yield about sustainability. Batik work is limited, mainly in Naphthol colour and partly in solubilized vat dye; it is applied to the fabric in cold condition. The excellence of batik word is, its natural creation of crack design with the help of wax, which is a good resisting material. Batik with natural colour is not practically possible, with the exhaust dyeing method. In this work, an attempt has been taken for batik work, with natural colour, which has a huge demand. This inspired the research to dye silk fabric with batik technique, using a combination of dyes namely: Indian Madder and Turmeric; Indian Madder and Marigold Petals; Turmeric and Marigold Petals. The composite dyes, mostly shade of yellow to red. Six cushion covers were prepared with the different techniques, mordants and dyes, and a preference for the colour combination and the batik effect were taken. It was said that, the samples were very impressive and a very good batik effect was produced by natural dyes. They also said that, it was a very good idea for reducing the environmental pollution. The study was very innovative and could be used for further researches.
\end{abstract}

KEYWORDS: Batik, Naphthol Dye, Vat Dye \& Natural Dye

Received: Aug 15, 2017; Accepted: Sep 05, 2017; Published: Sep 16, 2017; Paper Id.: IJTFTOCT20172

\section{INTRODUCTION}

"The beauty of batik lies in its simplicity and the fact that, you don't have to be an artist to achieve results. Some of the best effects in batik are often achieved by chance" informs fashion designer Singhal. D.

The word "Batik" is Indonesian in origin, and occurs as "Ambatik" in Javanese; it means "drawing" and "writing." These two words describe, what it means to print batik: to draw patterns and designs free hand with hot wax, followed by painting between the waxed sections. Batik is traditionally a handcrafted process, that started over 1,500 years ago. Batik is a method of dyeing or printing, by which the parts of the fabric is not intended to be dyed and are covered with hydrophobic material such as wax, paraffin, etc. The fabric is then dyed, and the wax acts as a resist, preventing selected areas of the fabric from absorbing dye. The process of waxing and dyeing is repeated several times, forming a multicolored image on the fabric. ${ }^{(2,3)}$ After the accidental synthesis of mauveine by Perkin in Germany, in 1856 and its subsequent commercialization, coal-tar dyes began to compete with natural dyes. 
Ironically, in 1996 Germany became the first country to ban certain azo dyes.

A scope of using natural dyes, as a possible substitute to ban azo-dyes. Traditionally, batik was printed in cold natural dyes, but with the influence of synthetic dyes, the Azoic dyes were used for batik printing. Now a days, reactive dyes and Azoic dyes are used for the batik. Now a days, with the increasing awareness of the environmental pollution and health hazards, associated with the synthesis and processing of synthetic dyes, caused the environments to raise the call "go back to the nature". Some of the synthetic dyes contain carcinogenic/toxic amine, or other such groups, which are harmful to the human body. In contrast to this, most of the natural dye is based on vegetable origins, which are Agra-renewable, bio-degradable and eco-friendly in nature (except a few which contain objectionable hazardous chemicals). The use of natural dyes in place of azo dye would reduce the environmental pollution, health hazards and many chemical causes. ${ }^{(1)}$ Natural dyes have a colour palette, which is very pleasing and different as compared to the synthetic azo dyes. ${ }^{(4,5)}$ This would also add value to various articles, that could be produced by batik using natural dyes. This inspired the investigator to carry out an experimental study of batik on silk, using natural dyes namely Indian Madder plus Turmeric; Indian Madder plus marigold petals and Turmeric plus marigold petals, and multi colour dyeing by varying different $\mathrm{pH}$ and mordant. And the percent transmission and colour data of the dyes under study were also analyzed.

Further, for the value addition to Khadi silk fabric, the investigator has made an effort to use the silk for the products. The possible variable was kept in mind and the numbers of samples were prepared. A series of samples were prepared with the three composite dyes (Indian Madder \& Turmeric, Turmeric \& Marigold petals, Marigold petals \& Indian Madder), different mordant with its selected concentration, two mordanting procedures like pre-mordanting and simultaneous mordanting, and variation in $\mathrm{pH}$ like acidic, neutral, alkali. Six cushion covers were prepared with the different techniques, and the preferences were taken from five experts in the field of Batik, printing and natural dyes. The experts gave their order of preference for the cushion covers, according to the colour combination and the Batik effect.

\section{METHOD AND MATERIALS}

\section{Natural Dyes}

Table 1: Indian Madder, Turmeric and Marigold Petals were used as Vegetable Colorants for this Work

\begin{tabular}{|c|l|l|l|l|l|l|}
\hline Sr. no. & Name of Dye & Botanical Name & Parts used & $\begin{array}{c}\text { Class of Dye } \\
\text { Based on } \\
\text { Chemical } \\
\text { Constitution }\end{array}$ & $\begin{array}{c}\text { Class of Dye } \\
\text { Based on its } \\
\text { Application }\end{array}$ & $\begin{array}{c}\text { Colouring } \\
\text { Component }\end{array}$ \\
\hline 1 & Indian Madder & Rubia cardifolia & Roots & Quinones & $\begin{array}{l}\text { Acid/Mordant/ } \\
\text { Disperse }\end{array}$ & Alizarin \\
\hline 2 & Turmeric & Curcuma Longa & Rhizome & $\begin{array}{l}\text { Diferuloyl } \\
\text { methane }\end{array}$ & Direct & Curcumin \\
\hline 3 & Marigold petals & Tagettes species & Flowers & $\begin{array}{l}\text { Flavanoide/ } \\
\text { Carotenoides }\end{array}$ & Direct/Acid & Lutein \\
\hline
\end{tabular}

Three combinations (composite dyes) were used

- Indian Madder and Turmeric

- Indian Madder and Marigold petals

- $\quad$ Turmeric and Marigold petals 


\title{
Selection of Fabric
}

Staple silk fabric was used for the study.

\section{Determination of Preliminary Data}

Fabric parameters including fiber type, mass, fabric count, structure and thickness were determined using standard test methods.

\section{Preparation of the Fabric}

The aim of the pretreatment is to improve quality, by removing the impurities and foreign matters thoroughly and uniformly, from the fabric and make the fabric suitable for follow up processing. Hence, the selected silk fabric was scoured and bleached.

The scouring was carried with 2 gms/ lit of non-ionic detergent, at a material-to-liquid ratio of 1:40. It was finally rinsed thoroughly in running water and dried.

The solution for bleach was prepared by $1 \% \mathrm{H}_{2} \mathrm{O}_{2}$ and 2 gms/lt sodium silicate, maintaining the material liquor ratio $1: 40$ at $50{ }^{\circ} \mathrm{C}$, for $30 \mathrm{~min}$. For the neutralization, $1 \%$ acetic acid was used for 5 minutes.

\section{Preparation of the Fabric for Dyeing}

Myrobalan has ample natural tannin, which is the most important ingredient in dyeing with natural dyes. Myrobalan treated fabrics have more affinity to natural dyes. Hence, the myrobalan treatment was done taking $4 \%$ myrobalan powder on the liquor. The material liquor ratio was kept as 1:40. Myrobalan powder was weighed according to the proportions, with respect to the weight of the fabric and liquor, and then the powder was soaked for 15 minutes in the required quantity of water. The water was then filtered, and this solution was used to give the myrobalan treatment, to the waxed fabric samples.

\section{Selection of Mordants and Mordanting Technique}

Natural dyes may require some mordanting agents, in order to produce an affinity between the fibre and the dye. Different mordants will give different results. The metallic mordants which were used for the study were

\author{
Alum: (Aluminum Potassium Sulfate) 10\% \\ Copper: (Copper Sulfate) $5 \%$ \\ Chrome: (Potassium Dichromate) 5\% \\ Iron: (Ferrous Sulfate) $5 \%$
}

\section{Mordanting Technique}

The simultaneous mordanting method was selected for the study. In simultaneously technique, mordanting and dyeing are done simultaneously.

\section{Variation in pH}

The dye from natural sources can be extracted in alkaline, acidic and aqueous methods. For getting various tints and shades, $\mathrm{pH}$ of dye bath were varied. Three different $\mathrm{pH}$ was used, i.e. acidic $(5 \mathrm{pH})$, neutral $(7 \mathrm{pH})$ and alkali $(9 \mathrm{pH})$. 


\section{Extraction of the Dye Solution}

The dye was calculated on the amount of liquor, required for dyeing. It is taken as $2 \%$ in the case of root, wood and barks dye source, and $4 \%$ in the case of leaves, petals or flowers. As the roots, bark and wood yield more colour than the petals.

The material liquor ratio was 1:40. The dye powder was weighed according to the quantity and the powder was steeped in water, according to the liquor ratio and the dye was extracted for 30-45 minutes of boiling. The liquor was maintained by occasionally adding distilled water to the extract in measured quantities. The extract was then allowed to cool and was filtered.

For the extraction of compost dyeing, each of these dyes were weighed individually and kept for extraction separately. After 30 minutes of extraction, the dye solution was filtered and kept aside for cooling and reuse it later on. The extracts were taken in 1:1 proportion, according to the material liquor ratio and the dyeing was carried out.

\section{Wax Coating and Dyeing}

Silk fabric was first scoured, bleached and then 5" x 5" size samples were cut. After this, the design prepared on a stencil was marked on the samples. The area to be resisted was waxed with molten wax of $60 \%$ Paraffin wax, and $40 \%$ Bees wax. The application was done with the help of brush, on either side of the samples. Simultaneous mordanting were done. The mordant of selected concentration was taken in the solution and then, it was added in the dye bath. After the dyeing and mordanting was completed, the sample was washed and was air dried. The samples were then dewaxed.

The dye application was carried out by means of the exhaust dyeing method. Material liquor ratio was 1:50.

\section{Removal of Wax}

For better removal of wax from the fabric after dyeing, the fabric was boiled for 5-7 minutes. Almost $90 \%$ was removed and rest $10 \%$ was removed by ironing at high temperature, keeping the fabric in between the two papers.

\section{Measurement of Color Strength}

The percent transmission and the colour strength value of dye solution were recorded from $400 \mathrm{~nm}$ to $700 \mathrm{~nm}$, at 10nm intervals. The absorption was measured on Premier 5100 Spectrometer, 5100 based on C.I.E lab.

\section{Preparation of Cushion Cover for the Effect of Batik}

Six cushion of 16"X 16"were prepared with different dye, mordants and procedure of dyeing.

Technique 1: single dye and single mordant was used. Marigold petal used as a dye and potassium dichromate as mordant. First, the silk was treated with Myrobalan and then the design was waxed on both sides of the fabric, and allowed to air dry. The fabric was then simultaneously mordanted, and dyed with the standardized recipe.

Technique 2: two dyes (Indian Madder and Turmeric) with two mordants (alum and potassium dichromate) were used. In this also, silk fabric was treated with myrobalan first. The design area was waxed and allowed to air dry. Then, the fabric was dyed with simultaneous dyeing in two stages, that is first with potassium dichromate and turmeric, then the other half diagonal dyed with alum, with Indian Madder. After dyeing was done, the abric was washed and dried to remove wax from the samples. 
Technique 3: composite dye with a single mordant was used. For the composite dyeing, Indian Madder and Turmeric dyes were used in equal proportion, and alum was used as a mordant. The area where the base colour was required in the silk fabric was waxed, after the wax dried Myrobalan treatment was given to the fabric. Then the sample was dyed with a combination of Dyes (Indian Madder and Turmeric), along with alum. After dyeing, the sample was dried and de-waxed.

Technique 4: multi-colour dyeing (two dyes with two mordants) was used. First, the area where the self silk colour was needed was waxed, and then myrobalan treatment was given to the sample. Then, the area where the colour of myrobalan was required was waxed again. Alum was used in the same bath, as used for dyeing (simultaneous dyeingmordanting) with marigold petals. The design was waxed again and after the sample dried it was dyed again with Indian madder, using potassium dichromate as a mordant. The dyed fabric was rinsed with water and finally the sample was dewaxed.

Technique 5: Composite dye was used with two mordants. Indian madder and Marigold petals as dyes, and for mordanting alum and copper sulphate were used. First, the area where copper sulphate was dyed with composite dyes was waxed, the fabric was washed after dyeing, the fabric was air dried and the dyed part of the design was waxed. The wax was removed from the part of the design, where simultaneous dyeing with alum was done. The fabric was dyed again with composite dyes. After dyeing, the fabric was washed and de-waxed.

Technique 6: A single dye (Turmeric) with four different mordants, i.e., alum, copper sulphate, potassium dichromate and ferrous sulphate. For the design, a myrobalan treated sample was taken. The whole sample was waxed except the design area, where the mordanting with alum was required. After the wax dried, the sample was simultaneously mordanted and dyed with alum and turmeric. After dyeing, the fabric was washed and air-dried. The part of the design that was mordanted with copper sulphate was de-waxed and the design, to be treated with alum was waxed. The fabric was dyed again with turmeric. Replication of the previous procedure was followed for potassium dichromate and ferrous sulphate. After the completion of dyeing with all four mordants, the fabric was washed and de-waxed

\section{Evaluation of Cushion Covers in Terms of Overall Effect of Batik}

The evaluation of cushion covers was done by a panel of five judges. They all were experts in the field of Batik, natural dyes and printing. The panel was first given information about the study and the variables used, and were asked to judge the variation of colour, kind of cracks for creating the batik effect. The cushion covers which were prepared by different techniques and procedures, were also ranked by the panel of judges keeping colour, aesthetics and crack effect in mind.

\section{RESULTS AND DISCUSSIONS}

Fabric

Scoured and bleached stable silk fabric of plain weave was used, for the study. Warp and weft yarns were 31 and 26 yarns $/ \mathrm{cm}^{2}$, respectively. Thickness of samples was $0.268 \mathrm{~mm}$, with a mass of $94 \mathrm{gms} / \mathrm{mt}^{2}$.

\section{Evaluation of Colour Palette in Terms of Percent Transmission and Overall Effect of Batik}

The colour palettes were evaluated in terms of percent transmission of the single dye, and three composite dyes. The $\mathrm{L}^{*}, \mathrm{a}^{*}, \mathrm{~b}^{*}$ values of different dyes were measured, on Premier 5100 Spectrometer, are shown in Table 1. 
Table 2: The Colour Data of Different Dyes

\begin{tabular}{|l|c|c|c|}
\hline \multicolumn{1}{|c|}{ Dyes liquor } & $\mathbf{L}^{*}$ & $\mathbf{a}^{*}$ & $\mathbf{b}^{*}$ \\
\hline Standard liquor & 99.394 & -1.416 & 3.973 \\
\hline Indian Madder & 99.596 & -0.515 & 2.897 \\
\hline Turmeric & 99.654 & -1.347 & 4.824 \\
\hline Marigold petals & 99.743 & -2.497 & 5.792 \\
\hline Indian Madder and Turmeric & 99.859 & -0.657 & 1.959 \\
\hline Indian Madder and Marigold petals & 99.820 & -0.890 & 2.606 \\
\hline Turmeric and Marigold petals & 99.881 & -0.731 & 1.980 \\
\hline
\end{tabular}

It was evident from the results that, percent transmission of Indian Madder, was lying in the region of reddish yellow. The percent transmission of turmeric was in the region of yellowish orange, while marigold dye gave olive green to brown, by varying mordants and $\mathrm{pH}$.

Combination of Indian Madder and Turmeric dye gave tints and shade of reddish orange. The percent transmission of Indian Madder and Marigold petals were tints and shades of yellow to red, while Turmeric and Merigold petal dye were in region of red and blue.

Colour Yield of Composite Dyes Namely: Indian Madder and Turmeric; Indian Madder and Marigold Petals; Turmeric and Marigold Petals

The main objective of the study was to obtain a color palette, and for this three dye composite, four mordants and three $\mathrm{pH}$ were exploited, and a colour palette of 36 shades were obtained by simultaneous mordanting.

It was evident from the results that, in the samples treated with the combination of two dyes, produced colour in between the two dyes which were combined.

Results shows that, the samples dyed with the combination of Indian Madder and Turmeric mordanted with all the four mordantes, got appealing batik effect. The simultaneous mordanting with four mordants dyed with Indian Marigold + Marigold petals and Turmeric + Marigold petals got very appealing response for the effect of batik.

The base colour of Turemric and Marigold; Madder and Turmeric samples do not appear, as visual as Indian Madder and Marigold petals. Colour palettes obtained with combination of teo dyes were very unique and elegant.

\section{Evaluation of Cushion Covers in Terms of Overall Aesthetic Appeal and Colors and Effects Produced}

After the colour yield test, the shade obtained was experimented with batik technique. Further, for the value addition to Khadi silk fabric, the investigator has made an effort to use the silk for the products. The possible variables were kept in mind, and the numbers of samples were prepared. A colour palette of 9 shades were developed, from multi colour (Plate 1).

The effect expected to be produced by multi-coloured dyeing, was to create darker cracks on lighter colour background. Samples were prepared for getting different colours, produced by the multi colour dyeing. Colour combinations of these samples were used for product making.

Samples were prepared with varying mordant in second dyeing. This dyeing was carried out on its self $\mathrm{pH}$. For the first dyeing samples, were mordanted with alum because, alum gave lighter shade as compared to potassium dichromate and ferrous sulphate. 
Nine samples prepared by following dyes and mordants:

Sample 1: Marigold petals with alum and Indian madder with alum

Sample 2: Marigold petals with alum and Indian madder with copper sulphate

Sample 3: Marigold petals with alum and Indian madder with potassium dichromate

Sample 4: Turmeric with alum and Indian madder with alum

Sample 5: Turmeric with alum and Indian madder with copper sulphate

Sample 6: Turmeric with alum and Indian madder with potassium dichromate

Sample 7: Turmeric with alum and Marigold petals with alum

Sample 8: Turmeric with alum and Marigold petals with copper sulphate

Sample 9: Turmeric with alum and Marigold petals with potassium dichromate

Marigold petals with alum and Indian madder with potassium dichromate, gives very brilliant result, and these combinations were used for final production of cushion covers. The sample had darker cracks of Indian Madder, on lighter background of Marigold.

After experimenting with different dyes, $\mathrm{pH}$, mordants and procedures, some combinations using various techniques were tried out, for preparations of a product i.e., cushion covers. The preferences were taken from five experts in the field of Batik, Printing and Natural dyes.

The experts were asked their opinion about the colour combination and the batik effect of six cushions. According to the expert, four cushion covers (Table 2) i.e., single dye with single mordant (Marigold with Potassium Dichromate), composite dye with single mordant (Indian Madder and Turmeric with Alum), multi-colour dyeing- two dyes with two mordants (Marigold Petals with Alum and Indian Madder with Potassium Dichromate) and single dye with four mordant (Turmeric with Alum, Copper sulphate, Potassium Dichromate and Ferrous Sulphate), were very appealing and rest two i.e., two dyes with two mordants (Indian Madder with Alum and Turmeric with Potassium Dichromate) and composite dye, with two mordants (Indian Madder and Marigold Petals with alum and Potassium Dichromate) were not as appealing.

The experts commented that, azo dyed batik gives very bright colour, but natural dyes give dull and earthy look. They also said that, the batik with natural dyes was very remarkable. They said that, the traditional craft of batik will again come in to fashion, with new look and effect. They also said that, it was a very good idea for reducing the environment pollution. The study was very innovative and could be used for further researches.

According to the opinion of the experts, cushion cover, wall hanging, lamp shades, hand bags, home furnishing articles, dress material, bed sheets, stoles and scarf, were the products which they thought the market would accept and would definitely be accepted.

Table 3: Opinion of Expertise Regarding the Colour Combination and Batik Effect of Six Cushion Covers

\begin{tabular}{|c|l|c|c|c|}
\hline Techniques & \multicolumn{1}{|c|}{ Dyes and Mordants Used. } & V.A & A & N.A \\
\hline 1 & Marigold with Potassium Dichromate & $*$ & \\
\hline 2 & $\begin{array}{l}\text { Indian Madder with Alum } \\
\text { Turmeric with Potassium Dichromate }\end{array}$ & & $*$ \\
\hline
\end{tabular}




\begin{tabular}{|c|c|c|c|c|}
\hline \multicolumn{5}{|c|}{ Table 3: Contd., } \\
\hline 3 & Indian Madder and Turmeric with Alum (Composite dyeing) & $*$ & & \\
\hline 4 & $\begin{array}{l}\text { Marigold Petals with Alum } \\
\text { Indian Madder with Potassium Dichromate (multi-colour dyeing) }\end{array}$ & $*$ & & \\
\hline 5 & $\begin{array}{l}\text { Indian Madder and Marigold Petals with alum and Potassium Dichromate } \\
\text { (composite Dyeing) }\end{array}$ & & $*$ & \\
\hline 6 & $\begin{array}{l}\text { Turmeric with Alum, Copper sulphate, Potassium Dichromate and Ferrous } \\
\text { Sulphate. }\end{array}$ & $*$ & & \\
\hline
\end{tabular}

The respondents were asked to rank the cuhion cover (Graph 1 and Plate 2), regarding the colour combination and batik effect, and the responses shows that, technique 4 was given first rank with the score of 28 , in terms of batik effect and colour produced by dyeing. The techniques 3 and 6 , were ranked as second and third with score of 25 and 18 , respectively. Technique 5 was ranked as sixth, with the score of 6.

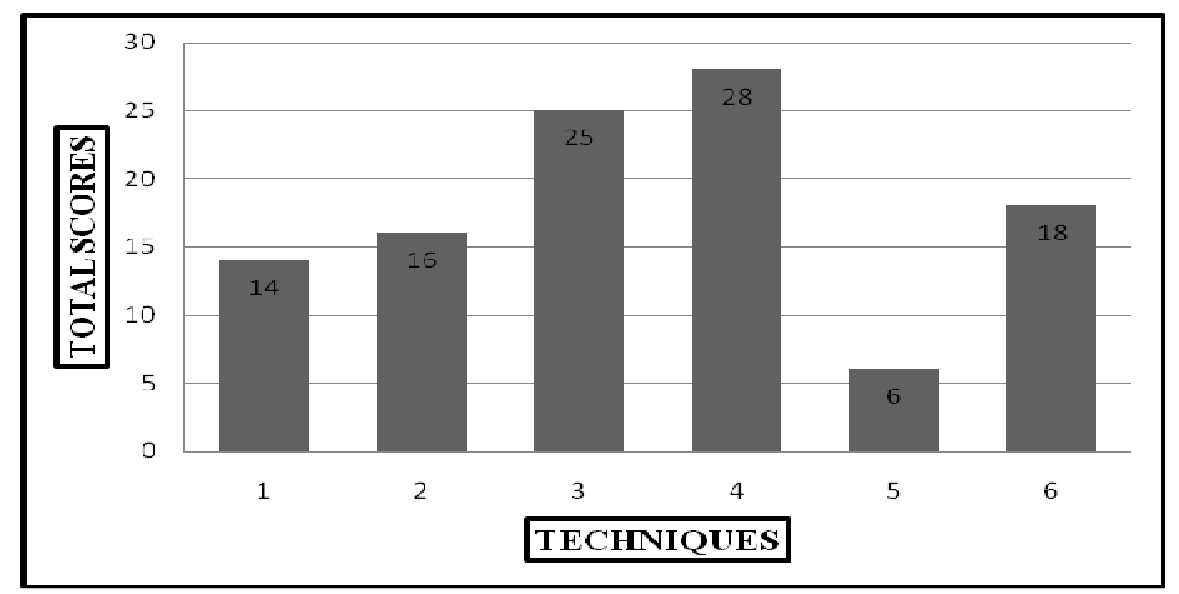

Graph 1: Distribution of the Expertise's Opinion Regarding the Ranking of Cushion Covers

\section{CONCLUSIONS}

The process of batik work with natural dyes is an innovative method, which produces a unique design on the fabric.

The $\mathrm{L}^{*}, \mathrm{a}^{*}, \mathrm{~b}^{*}$ value of dye show that, the Indian madder gives different shades of red, turmeric gives tint and shades of yellow orange and marigold gives shade of olive green to brown. And the composite dyes give mostly shades of yellow to red.

Base colour of Turmeric and Marigold; Indian Madder and Turmeric samples, does not appear as visual as Indian Madder and Marigold petals.

The judgment of expertise, regarding the appreciation of concept of Batik with natural dyes, as per consumer gives positive response. All five judges agree with the concept of batik, with natural dyes. They said that, the traditional craft of batik will again come in to fashion, with new look and effect. They liked the colours, which were produced form natural dyes. The study was very innovative and could be used for further researches.

\section{REFERENCES}

1. Dayal, R., \& Dobhal, P.C.(2001). Natural dyes from some Indian plants. Colourage, 48(8), 33-38.

2. Goyal, S. (1987) An experimental study in Batik on designing with different blocks and resist' (Unpublished Master thesis 
(Home)), The M.S. University of Baroda, Gujarat, India.

3. Divya Lekshmi R. B \& Ravi D, Extraction of Natural Dyes from Selected Plant Sources and its Application in Fabrics, International Journal of Textile and Fashion Technology (IJTFT), Volume 3, Issue 2, May - June 2013, pp. 53-60

4. Grewal, H. (1984) An experimental study on the combination of Batik and Tie and Dye (Unpublished Master thesis (Home)), The M.S. University of Baroda, Gujarat, India.

5. Jain, M. (1982) An experimental study of various resists and techniques used in Batik (Unpublished Master thesis (Home)), The M.S. University of Baroda, Vadodara, Gujarat, India.

6. Ranganathan, K., \& Amsamani,S. (2006). Natural dyed batik fabric. Asian Textile Journal, 2, 61-64.

\section{APPENDICES}

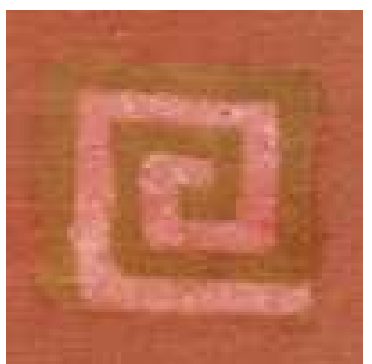

Sample 1

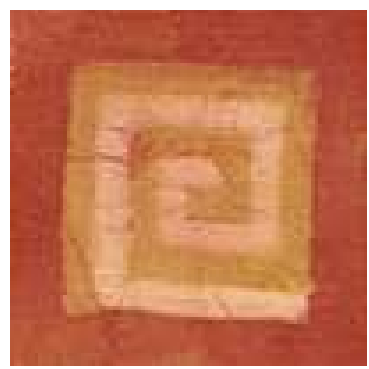

Sample 4

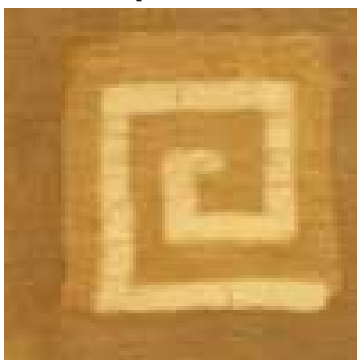

Sample 7

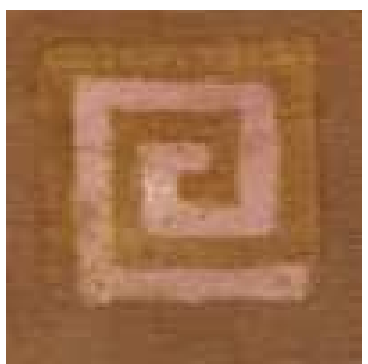

Sample 2

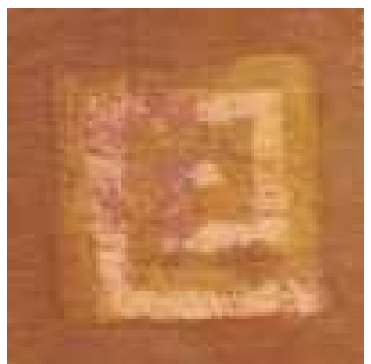

Sample 5

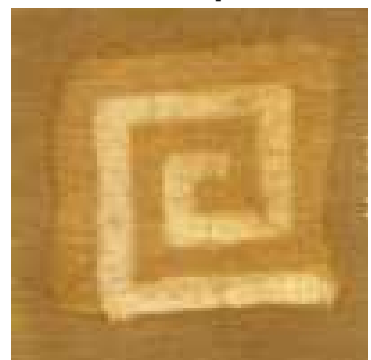

Sample 8

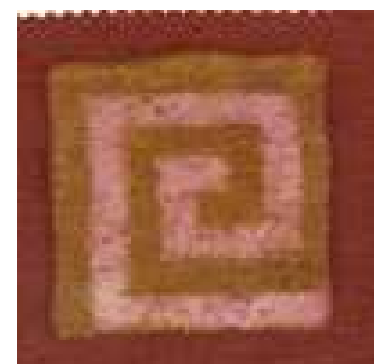

Sample 3

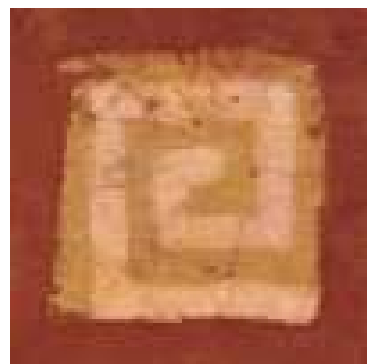

Sample 6

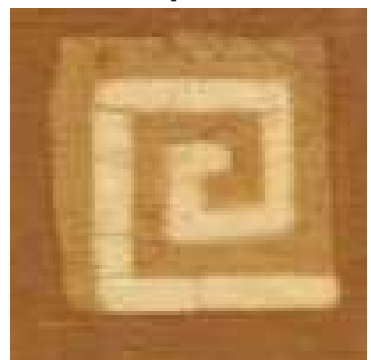

Sample 9

Plate 1: Color Palette of Multi-Color Dyed Samples with Indian Madder, Marigold Petals Turmeric by Simultaneous Mordanting with Various Metal Mordants

Sample 1: Marigold Petals with Alum, Indian Madder with Alum

Sample 2: Marigold Petals with Alum, Indian Madder with Copper sulphate

Sample 3: Marigold Petals with Alum, Indian Madder with Potassium Dichromate

Sample 4: Turmeric with Alum, Indian Madder with Alum 
Sample 5: Turmeric with Alum, Indian Madder with Copper sulphate

Sample 6: Turmeric with Alum, Indian Madder with Potassium Dichromate

Sample 7: Turmeric with Alum, Marigold Petals with Potassium Dichromate

Sample 8: Turmeric with Alum, Marigold Petals with Copper sulphate

Sample 9: Turmeric with Alum, Marigold Petals with Alum
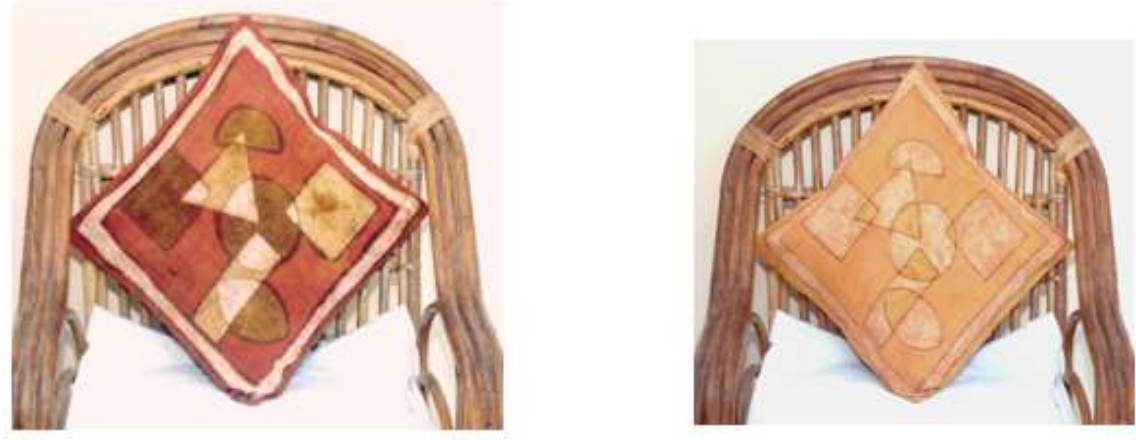

Rank-1 Technique- 4 Rank-2 Technique-3
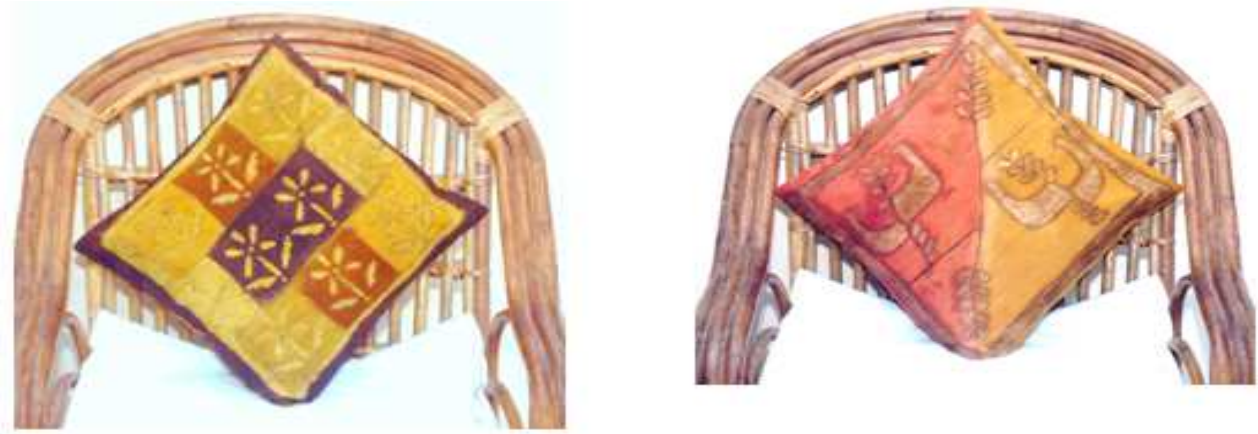

Rank-3 Technique-6 Rank-4 Technique-2
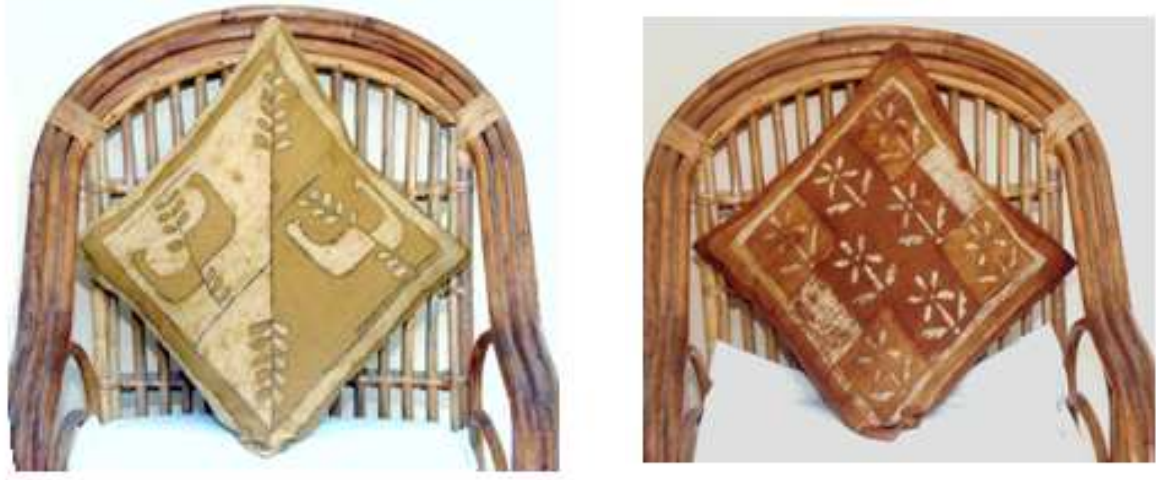

Rank-5 Technique-1 Rank-6 Technique-5

Plate 2: Ranking of Product Line of Cushion Covers in Silk Using Combination of Dyes 